\title{
Atividades antiúlcera e antioxidante do extrato de folhas de Syzygium jambos (L.) Alston (Myrtaceae)
}

\author{
Raquel S. Donatini, ${ }^{1}$ Tati Ishikawa, ${ }^{1}$ Silvia B. M. Barros, ${ }^{2}$ Elfriede M. Bacchi ${ }^{* 1}$ \\ ${ }^{1}$ Programa de Pós-graduação em Fármaco e Medicamentos, Faculdade de Ciências Farmacêuticas, \\ Universidade de São Paulo, Av. Lineu Prestes, 580, 05508-900 São Paulo-SP, Brasil, \\ ${ }^{2}$ Departamento de Análises Clínicas e Toxicológicas, Faculdade de Ciências Farmacêuticas, Universidade de \\ São Paulo, Av. Lineu Prestes, 580, 05508-900, São Paulo-SP, Brasil
}

\begin{abstract}
RESUMO: Syzygium jambos (L.) Alston, Myrtaceae, é empregado na medicina popular como digestivo e antiinflamatório. A triagem fitoquímica da droga pulverizada (folhas) indicou a presença de flavonóides, taninos e óleo volátil. O extrato hidroetanólico a $70 \%$ das folhas de $S$. jambos foi preparado por percolação e liofilizado. O conteúdo de taninos das folhas e do extrato foi calculado, respectivamente, em $21,9 \%$ e $43,3 \%$. O teor de flavonóides foi de $0,6 \%$ (folhas) e $1,2 \%$ (extrato). A administração oral prévia do extrato $(400 \mathrm{mg} / \mathrm{kg})$ a ratos Wistar reduziu significativamente as lesões gástricas induzidas por etanol acidificado. No modelo de úlcera subcrônica, com indução de lesão gástrica utilizando ácido acético a 30\%, o tratamento com o extrato $(400 \mathrm{mg} / \mathrm{kg})$ não apresentou resultado significativo. A atividade antioxidante do extrato foi avaliada através dos modelos de lipoperoxidação e de medida de capacidade seqüestrante de radicais DPPH. Os valores obtidos de $\mathrm{Q}_{1 / 2}(\mathrm{MDA})$ e $\mathrm{CE}_{50}(\mathrm{DPPH})$ foram, respectivamente, 0,17 $\mu \mathrm{g} / \mathrm{mL}$ e $5,68 \mu \mathrm{g} / \mathrm{mL}$.
\end{abstract}

Unitermos: Syzygium jambos, Myrtaceae, atividade antiúlcera, atividade antioxidante.

\begin{abstract}
Antiulcerogenic and antioxidant activities of leaf extract of Syzygium jambos (L.) Alston (Myrtaceae)". Syzygium jambos (L.) Alston, Myrtaceae, is commonly employed in folk medicine as digestive and anti-inflammatory. Phytochemical screening of the powdered dried leaves indicates the presence of flavonoids, tannins and essential oil. Hydroethanol extracts $(70 \%)$ were prepared by percolation and freeze-drying. The tannin content of dried leaves and extract was, respectively, $21.9 \%$ and $43.3 \%$. The flavonoid content was $0.6 \%$ (dried leaves) and $1.2 \%$ (extract). Previous oral administration of $S$. jambos leaves extract $(400 \mathrm{mg} / \mathrm{kg})$ to rats reduced significantly gastric injury induced by $\mathrm{HCl} /$ ethanol. At the subcronic ulcer model by induction with $30 \%$ acetic acid the results were not significant. In vitro antioxidant activity of $S$. jambos extract was evaluated by malondialdehyde (MDA) and DPPH free radical method. The $\mathrm{Q}_{1 / 2}$ for MDA assay was $0.17 \mu \mathrm{g} / \mathrm{mL}$ and the $\mathrm{EC}_{50}$ for DPPH assay was $5.68 \mu \mathrm{g} / \mathrm{mL}$.
\end{abstract}

Keywords: Syzygium jambos, Myrtaceae, antiulcerogenic activity, antioxidant activity.

\section{INTRODUÇÃO}

A úlcera péptica constitui desordem do trato gastrintestinal que afeta milhões de pessoas em todo o mundo, e têm sido, há bastante tempo, uma das causas mais importantes de morbidade e mortalidade (Birdane et al., 2007).

A etiologia da úlcera gástrica ainda não está totalmente elucidada. Fato conhecido é que ocorre um desequilíbrio entre os fatores agressivos (secreção de ácido e pepsina) e os fatores citoprotetores da mucosa gástrica (secreção de bicarbonato, secreção de muco e produção de prostaglandinas) (Borrelli \& Izzo, 2000). A infecção por Helicobacter pylori, o largo uso de antiinflamatórios não-esteróides, o consumo de cigarros e bebidas alcoólicas contribuem para a formação das úlceras gástricas (Brunton, 1996).
Os medicamentos utilizados atualmente no tratamento de úlceras gástricas são os antiácidos, os anticolinérgicos, os inibidores da bomba de prótons e os antagonistas de receptor $\mathrm{H}_{2}$ (Rang et al., 2004). No entanto, estes fármacos podem ocasionar reações adversas graves, como trombocitopenia (Zlabek \& Anderson, 2002), nefrite intersticial aguda (Ra \& Tobe, 2004), nefrotoxicidade e hepatotoxicidade (Fisher \& Le Couteur, 2001), reações anafiláticas (Gonzalez et al., 2002), ginecomastia e impotência (Sabesin, 1993).

Além disso, no Brasil, o tratamento de úlceras gástricas é bastante caro, não sendo acessível a grande parte da população (Hiruma-Lima et al., 2006). O tratamento das úlceras pépticas, dessa forma, constitui ainda um grande desafio e torna-se necessário o desenvolvimento de novos agentes terapêuticos mais eficazes, menos tóxicos e de custo mais baixo. 
Diversas substâncias de origem vegetal, entre elas flavonóides, taninos e terpenóides, têm apresentado atividade antiúlcera bastante significativa (Borrelli \& Izzo, 2000; Rodriguez et al., 2004 Marques et al., 2006), demonstrando o grande potencial das plantas medicinais como fontes alternativas para o tratamento de úlceras gástricas.

A família Myrtaceae compreende cerca de 100 gêneros e 3.500 espécies distribuídas predominantemente em regiões tropicais e subtropicais (Barroso, 1984), incluindo espécies frutíferas e medicinais (Agra et al., 2007, 2008). As folhas são largamente utilizadas como antiiflamatórias, cicatrizantes, anti-sépticas e, especialmente, como antidiarreicas (Di Stasi \& HirumaLima, 2002; Lorenzi \& Abreu Matos, 2002).

Pertencente à família Myrtaceae, Syzygium jambos (L.) Alston é árvore de origem asiática, nativa da Índia e Malásia. Seus frutos são édulos, muito apreciados pelo aroma agradável (Pio Correa, 1969), e empregados como diuréticos, digestivos e antifebris (Cravo, 1994). As folhas são empregadas na medicina popular como digestivas e antiinflamatórias (Slowing et al., 1996).

Das folhas de $S$. jambos foram isolados dois glicosídeos flavonoídicos (miricetina e quercetina 3-O- $\beta$-D-xilopiranosil (1-2) $\alpha$-L-ramnopiranosídeos), que apresentaram atividade antiinflamatória mais significativa que os fármacos empregados como referência (fenilbutazona e indometacina) em modelo de edema de pata em camundongos (Slowing et al., 1996).

O objetivo deste trabalho foi avaliar a atividade antiulcerogênica do extrato hidroetanólico a $70 \%$ obtido das folhas de S. jambos através dos modelos de indução por etanol acidificado e por ácido acético, além de determinar sua ação antioxidante através da medida da capacidade seqüestrante de radicais DPPH e da inibição da lipoperoxidação espontânea de homogeneizado de cérebro de ratos in vitro.

\section{MATERIAL E MÉTODOS}

\section{Material vegetal}

As folhas de Syzygium jambos (L.) Alston foram coletadas durante a floração, na Escola Superior de Agricultura Luiz de Queiroz - ESALQ - USP, em Piracicaba, São Paulo, Brasil. Uma exsicata, identificada por Fiorella Fernanda Mazine, foi depositada no herbário da mesma Escola sob $n^{\circ}$ ESA 84432.

\section{Preparação do extrato}

As folhas de $S$. jambos foram secas em estufa com circulação de ar forçada, a $40{ }^{\circ} \mathrm{C}$ por 48 horas, e pulverizadas em moinho de facas e martelos passando por tamis de $1 \mathrm{~mm}$. O extrato foi preparado através de percolação, sendo empregado como solvente etanol a $70 \%$. Após a extração, o etanol foi evaporado à pressão reduzida e o extrato aquoso remanescente foi liofilizado.

\section{Estudos fitoquímicos}

As folhas pulverizadas de $S$. jambos foram testadas quanto à presença de alcalóides, flavonóides, saponinas, derivados antracênicos, esteróides e taninos (Matos, 1988). O teor de taninos na droga pulverizada e no extrato foi avaliado de acordo com a European Pharmacopoeia (1996) e o teor de flavonóides foi determinado conforme descrito por Wichtl (1971), através de reação com cloreto de alumínio e leitura em espectrofotômetro a $425 \mathrm{~nm}$.

\section{Animais}

Os animais utilizados nos ensaios farmacológicos foram provenientes do Biotério da Faculdade de Ciências Farmacêuticas da Universidade de São Paulo. Foram mantidos durante 5 dias em adaptação ao ambiente do ensaio, em gaiolas apropriadas, com ciclo de claro-escuro regulado para 12/12 h. Para a avaliação da atividade antiúlcera, foram utilizados ratos Wistar fêmeas (150 a 180 g). No teste de atividade antioxidante, foram utilizados ratos Wistar machos (aproximadamente $300 \mathrm{~g}$ ). Os experimentos foram aprovados pela Comissão de Ética em Experimentação Animal da FCF/USP (Protocolo CEEA n ${ }^{\circ}$ 127).

\section{Úlcera aguda - indução por etanol/HCl}

A avaliação da atividade antiúlcera aguda do extrato hidroetanólico a $70 \%$ liofilizado de folhas de $S$. jambos (EHEL) foi realizada em ratos Wistar fêmeas, conforme descrito por Mizui \& Doteuchi (1983). Os animais foram divididos em 5 grupos, e mantidos em jejum por 12 horas antes da administração oral de extrato (100, 200 e $400 \mathrm{mg} / \mathrm{kg})$, lansoprazol (30 mg/kg) e água $(1 \mathrm{~mL} / 100 \mathrm{~g})$. Trinta minutos após o tratamento, todos os animais receberam, por via oral, solução $0,3 \mathrm{M} \mathrm{HCl} / 60 \%$ EtOH $(1 \mathrm{~mL} / 100 \mathrm{~g})$. Os animais foram mortos após uma hora da administração do indutor. Os estômagos foram retirados, abertos pela grande curvatura e as ulcerações foram avaliadas.

\section{Úlcera subcrônica - indução por ácido acético a 30\%}

A atividade antiúlcera subcrônica do EHEL de $S$. jambos foi avaliada de acordo com Takagi et al. (1969). Fêmeas Wistar foram divididas em 3 grupos, mantidas em jejum por $12 \mathrm{~h}$ antes da indução de úlcera gástrica. Nos animais anestesiados, foi realizada uma incisão epigástrica e, com o estômago parcialmente exposto, foram injetados $0,05 \mathrm{~mL}$ de solução de ácido 
acético a 30\% na camada subserosa da porção glandular da parede anterior. No segundo dia após a indução, os animais foram tratados com doses diárias do extrato $(400 \mathrm{mg} / \mathrm{kg})$, cimetidina $(100 \mathrm{mg} / \mathrm{kg})$ e água $(1 \mathrm{~mL} / 100$ g). Os animais foram mortos após 12 dias de tratamento; os estômagos foram retirados, abertos através da grande curvatura e as ulcerações foram avaliadas.

\section{Atividade antioxidante - medida de MDA}

A atividade antioxidante do EHEL foi avaliada in vitro de acordo com método proposto por Stocks et al. (1974), baseado na inibição da lipoperoxidação espontânea de homogeneizado de cérebro de ratos, quando incubado em condições controladas de temperatura e oxigenação. Malonildialdeído (MDA) foi empregado como parâmetro para avaliação da lipoperoxidação. Ratos Wistar machos foram anestesiados e o cérebro foi perfundido através da veia cava superior com solução tampão $140 \mathrm{mM} \mathrm{NaCl}, 40$ $\mathrm{mM}$ potássio, $\mathrm{pH} 7,4$, removido e homogeneizado com a mesma solução tampão $(1: 4 \mathrm{p} / \mathrm{v})$. Este homogeneizado foi centrifugado por 15 minutos a $3000 \mathrm{rpm} \mathrm{a} 4{ }^{\circ} \mathrm{C}$. O sobrenadante foi diluído em três vezes seu volume de solução tampão fosfato-salina. Porções $(3 \mathrm{~mL})$ do homogeneizado diluído foram transferidas para uma série de erlenmeyers. Foram adicionadas alíquotas (50 $\mu \mathrm{L}$ ) de diferentes concentrações do EHEL de $S$. jambos em solução hidroetanólica a $35 \%$, em triplicata. Foram retiradas imediatamente alíquotas para medida de MDA em tempo-zero. Os erlenmeyers foram transferidos para banho de água a $37^{\circ} \mathrm{C}$ e permaneceram em incubação por exatamente $1 \mathrm{~h}$. As concentrações de MDA no tempo-zero e após $1 \mathrm{~h}$ de incubação foram medidas através de reação com ácido tiobarbitúrico (TBA). A 4 $\mathrm{mL}$ do homogeneizado foi adicionado $1 \mathrm{~mL}$ de ácido tricloroacético a $5 \%$; as proteínas precipitadas foram removidas por centrifugação. $\mathrm{O}$ sobrenadante $(1 \mathrm{~mL})$ foi aquecido com $1 \mathrm{~mL}$ de solução aquosa de ácido tiobarbitúrico a $0,67 \%$ por $20 \mathrm{~min}$ a $100{ }^{\circ} \mathrm{C}$. Após $20 \mathrm{~min}$ em banho de gelo e $20 \mathrm{~min}$ em temperatura ambiente, a absorbância foi medida a $535 \mathrm{~nm}$. O cálculo da capacidade antioxidante foi baseado na seguinte equação:

$$
\% \mathrm{CAOx}=1-\underline{\mathrm{T}}_{\underline{1}} \frac{(\text { amostra })-\mathrm{T}_{0}}{(\text { amostra })} \times 100
$$

Onde: $\mathrm{T}_{1}=$ leitura espectrofotométrica do tempo 1hora (incubadas)

$$
\mathrm{T}_{0}=\text { leitura espectrofotométrica do tempo zero }
$$

\section{Capacidade seqüestrante de radicais DPPH}

A capacidade seqüestrante de radicais DPPH (1,1-difenil-2-picril-hidrazila) foi realizada de acordo com Mensor et al. (2001). Porções de solução-estoque do EHEL (100 $\mu \mathrm{g} / \mathrm{mL})$ foram diluídas em etanol, até concentrações finais de 25, 10, 6.25, 3.125 e $2 \mu \mathrm{g} / \mathrm{mL}$. Solução etanólica de DPPH $0,3 \mathrm{mM}(1 \mathrm{~mL})$ foi adicionada a $2,5 \mathrm{~mL}$ das soluções de diferentes concentrações e as misturas reagiram em temperatura ambiente. Após 30 min a absorbância foi medida a $518 \mathrm{~nm}$ e convertida em porcentagem de capacidade antioxidante (AA) usando a seguinte formula:

$$
\mathrm{AA} \%=100-\underline{(\mathrm{Abs}} \underline{\underline{\text { EHEL }}} \frac{\left.-\mathrm{Abs}_{\text {branco }}\right) \times 100}{\mathrm{Abs}_{\text {controle }}}
$$

Etanol $(1.0 \mathrm{~mL})$ adicionado à solução de extrato $(2.5 \mathrm{~mL})$ foi usado como branco. Solução de DPPH (1.0 mL; $0.3 \mathrm{mM})$ adicionada a etanol $(2.5 \mathrm{~mL})$ foi usada como controle negativo. Os controles positivos foram os mesmos utilizados como soluções-padrão. Os valores médios da capacidade antioxidante $\left(\mathrm{EC}_{50}\right)$ foram calculados através da regressão linear, plotando-se a porcentagem de atividade antioxidante em função de diferentes concentrações de extrato, determinados em triplicata e em três testes diferentes.

\section{Análise estatística}

Os valores foram expressos como média \pm erro padrão. A avaliação da atividade antiulcerogênica foi calculada usando análise de variância (ANOVA). A porcentagem da área relativa de lesão foi calculada por transformação em arco-seno e teste t-Student. Diferenças significativas foram consideradas para $\mathrm{p}<$ 0,05 .

\section{RESULTADOS E DISCUSSÃO}

Entre as diversas doenças de grande incidência entre a população, as úlceras gástricas e duodenais representam uma das mais importantes, pois afetam um número considerável de pessoas em todo o mundo, sendo citadas, por alguns autores, como "a nova praga do século 21" (Hiruma-Lima et al., 2006).

Recentemente, muitos estudos têm sido feitos para explorar novos agentes antiúlcera de fontes naturais, e a atividade antiúlcera de diversos compostos químicos isolados de vegetais tem sido determinada (Borrelli \& Izzo, 2000; Lewis \& Hanson, 1991).

No Brasil, diversos extratos vegetais são utilizados na medicina popular para o tratamento de desordens digestivas, incluindo úlceras gástricas (Albiero et al., 2002; Gonzalez et al., 2001; Gonzalez \& Di Stasi, 2002; Mota et al., 2008; Silvério et al., 2008).

Inúmeros fatores, como o aumento da permeabilidade vascular, da motilidade intestinal, da atividade vagal, a diminuição do fluxo sanguíneo gástrico e dos níveis de prostaglandinas, exercem 
importante papel na patogênese das úlceras gástricas (Birdane et al., 2007). Dessa forma, vários modelos experimentais podem ser utilizados na tentativa de elucidar o mecanismo de ação de extratos vegetais.

O modelo de indução por etanol acidificado avalia, entre outras, a atividade de substâncias citoprotetoras. O etanol produz lesões necróticas na mucosa gástrica e a presença de ácido clorídrico acelera e agrava esse processo (Mizui \& Doteuchi, 1983). As ulcerações induzidas por etanol não são inibidas por substâncias que interferem na secreção de ácido, como a cimetidina, mas são inibidas por agentes que aumentam os fatores de defesa da mucosa, como, por exemplo, as prostaglandinas (Robert, 1979).

O mecanismo da lesão induzida por etanol é bastante variado, incluindo a redução da secreção de bicarbonato e da produção de muco (Marhuenda et al., 1993), danos ao fluxo sangüíneo gástrico e lesão de células da mucosa (Birdane et al., 2007). As lesões gástricas induzidas por etanol são também associadas à produção excessiva de radicais livres, que atacam constituintes celulares essenciais como ácidos nucléicos, proteínas e lipídeos (La Casa et al., 2000). O aumento do conteúdo de peróxidos lipídicos e radicais livres derivados de oxigênio resulta em alterações significativas em nível celular e causa danos às membranas, morte celular, esfoliação e erosão epitelial (Birdane et al., 2007).

No modelo de indução de úlcera gástrica por etanol $/ \mathrm{HCl}$, o EHEL de $S$. jambos apresentou atividade dose-dependente, sendo que a dose de 400 $\mathrm{mg} / \mathrm{kg}$ apresentou, em relação ao grupo controle, resultados extremamente significativos $(\mathrm{p}<0,001)$ na Área Total de Lesão (ATL - mm²) $(58,88 \pm 28,20$ EHEL x 320,70 $\pm 36,86$ controle) e Área Relativa de Lesão (ARL - \%) $(9,11 \pm 2,33$ EHEL x 26,11 $\pm 1,69$ controle). Nessa dose, o EHEL foi inclusive mais eficaz do que o fármaco empregado como referência (lansoprazol), que apresentou ATL e ARL de, respectivamente, 126,45 \pm 39,70 e 15,31 $\pm 2,15$ ( $p<0,01$ em comparação ao grupo controle) (Tabela 1).

As lesões crônicas induzidas por ácido acético são mais semelhantes à úlcera humana, tanto no aspecto macroscópico como microscópico. O ácido acético induz lesões gástricas que envolvem a camada muscular do estômago, e que não curam com o tempo. Neste modelo, resultados significativos foram obtidos com o emprego de substâncias que estimulam a proliferação de células do epitélio gástrico (Takagi et al., 1969). Além disto, existem indícios de que os radicais livres gerados pelos neutrófilos podem representar importante fator no retardo da cura de lesões gástricas induzidas por ácido acético (Lima et al., 2006).

O EHEL de $S$. jambos não apresentou, neste modelo, resultados significativos em comparação ao grupo controle (Tabela 2).

A presença de flavonóides e taninos, verificada na triagem fitoquímica da droga, pode ser responsável pela ação antiúlcera do extrato. O teor de taninos verificado na droga pulverizada foi de $21,9 \%$ e, no extrato, de $43,3 \%$. A quantificação de flavonóides totais, calculados como quercetina, indicou presença de $0,6 \%$ de flavonóides totais na droga vegetal e 1,2\% no extrato.

Os taninos possuem a propriedade de formar complexos com macromoléculas, como proteínas e polissacarídeos. Provavelmente essa complexação leve à formação de uma camada protetora na mucosa do estômago, tornando-a menos permeável e mais resistente a agressões químicas ou mecânicas (Mello \& Santos, 2004). Isto pode explicar, em parte, a atividade antiúlcera preventiva do extrato. Aos flavonóides atribuem-se o aumento do conteúdo local de prostaglandinas, a diminuição da secreção de histamina, a inibição da bomba de prótons e a inibição do H. pylori

Tabela 1. Efeito do extrato de folhas de Syzygium jambos e de lansoprazol em lesões gástricas induzidas por etanol/HCl em ratos.

\begin{tabular}{lcccc}
\hline Tratamento (p.o.) & Dose $(\mathrm{mg} / \mathrm{kg})$ & $n$ & Área total de lesão $\left(\mathrm{mm}^{2}\right)$ & Área relativa de lesão $(\%)$ \\
\hline Controle & - & 7 & $320,70 \pm 36,86$ & $26,11 \pm 1,69$ \\
Lansoprazol & 30 & 7 & $126,45 \pm 39,70 * *$ & $15,31 \pm 2,15 * *$ \\
Extrato & 100 & 7 & $217,42 \pm 27,62$ & $20,94 \pm 1,57$ \\
Extrato & 200 & 7 & $146,19 \pm 38,76^{*}$ & $16,90 \pm 2,15 *$ \\
Extrato & 400 & 7 & $58,88 \pm 28,20^{* * *}$ & $9,11 \pm 2,33 * * *$ \\
\hline
\end{tabular}

Resultados expressos em média \pm erro padrão. ANOVA: $* \mathrm{p}<0,05 ; * * \mathrm{p}<0,01 ; * * * \mathrm{p}<0,001$.

$n$ corresponde ao número de animais em cada grupo experimental.

Tabela 2. Efeito do extrato de folhas de Syzygium jambos e da cimetidina em lesões gástricas induzidas por ácido acético a 30\% em ratos.

\begin{tabular}{lcccl}
\hline Tratamento (p.o.) & Dose $(\mathrm{mg} / \mathrm{kg})$ & $n$ & Área total de lesão $\left(\mathrm{mm}^{2}\right)$ & Área relativa de lesão $(\%)$ \\
\hline Controle & - & 10 & $60,24 \pm 5,59$ & $12,63 \pm 0,48$ \\
Cimetidina & 100 & 10 & $20,67 \pm 1,77 * * *$ & $7,53 \pm 0,29 * * *$ \\
Extrato & 400 & 10 & $57,00 \pm 6,13$ & $12,08 \pm 0,75$ \\
\hline
\end{tabular}

Resultados expressos em media \pm erro padrão. ANOVA: *** $\mathrm{p}<0,001$.

$n$ corresponde ao número de animais em cada grupo experimental. 
(Borreli \& Izzo, 2000).

Outro possível mecanismo envolve a atividade antioxidante atribuída aos flavonóides e taninos, uma vez que os radicais livres representam um fator importante na formação de lesões ulcerativas e erosivas do trato gastrintestinal (Borrelli \& Izzo, 2000; Carbonezi et al., 2007). As lesões gástricas induzidas por etanol são resultantes de danos diretos às células da mucosa, decorrentes da hiperoxidação de lipídeos (Puurunen et al., 1980) e da formação de radicais livres que atacam moléculas como enzimas, proteínas ou receptores (Pihan et al., 1987). Desta forma, compostos antioxidantes podem ser ativos neste modelo experimental, produzindo atividade antiulcerogênica.

A medida da atividade antioxidante in vitro do EHEL das folhas de S. jambos foi realizada segundo método preconizado por Stocks et al. (1974), que avalia a inibição da lipoperoxidação espontânea de homogeneizado de cérebro de rato, quando incubado em condições controladas de temperatura e oxigenação. $\mathrm{O}$ malonildialdeído (MDA) é um dos produtos de oxidação de ácidos graxos polinsaturados, que reage com o ácido tiobarbitúrico (TBA), formando um complexo de coloração rosa, que tem um máximo de absorção no comprimento de onda $535 \mathrm{~nm}$. Neste modelo, o EHEL de $S$. jambos apresentou $\mathrm{Q}_{1 / 2}$ (concentração necessária para atingir $50 \%$ da capacidade antioxidante) de 0,17 $\mu \mathrm{g} / \mathrm{mL}$, indicando capacidade antioxidante superior a de extratos considerados promissores, como os de Pothomorphe umbellata (raiz - 4,4 $\mu \mathrm{g} / \mathrm{mL}$, caule - 19,3 $\mu \mathrm{g} / \mathrm{mL}$, folhas - 38,5 $\mu \mathrm{g} / \mathrm{mL}$ ) (Barros et al., 1996), e de extratos hidroalcoólicos de folhas de outras espécies de Myrtaceae (Eugenia uniflora - 0,578 $\mu \mathrm{g} / \mathrm{mL}$, Campomanesia xanthocarpa - 0,29 $\mu \mathrm{g} / \mathrm{mL}$ ) (Auricchio, 2001; Markman, 2002), entre outras (Iha et al., 2008).

DPPH é um radical livre estável em temperatura ambiente, que produz uma solução violeta em etanol. É reduzido na presença de substâncias antioxidantes, ocasionando a descoloração dessas soluções etanólicas (Mensor et al., 2001). Na avaliação da capacidade seqüestrante de radicais DPPH, o extrato apresentou $\mathrm{EC}_{50}$ de $5,68 \mu \mathrm{g} / \mathrm{mL}$, sendo esta atividade superior à do extrato de Ginkgo biloba $\left(\mathrm{EC}_{50}=44,72\right.$ $\mu \mathrm{g} / \mathrm{mL})$ e da própria rutina $\left(\mathrm{EC}_{50}=14,16 \mu \mathrm{g} / \mathrm{mL}\right)$, substância reconhecida por sua ação antioxidante, ambos avaliados por Mensor et al. (2001) através do mesmo método.

Concluímos que o extrato hidroetanólico a $70 \%$ de folhas de Syzygium jambos, na dose de 400 $\mathrm{mg} / \mathrm{kg}$, apresenta um excelente efeito preventivo de lesões gástricas no modelo de indução aguda em ratos. O mecanismo desta atividade provavelmente está relacionado a fatores citoprotetores e à forte atividade antioxidante apresentada pelo extrato. São necessários outros modelos experimentais de ulceração para a compreensão do mecanismo de ação da atividade antiúlcera desta espécie, no entanto pode-se descartar uma possível ação trófica da gastrina, como por exemplo, a estimulação da proliferação das células da mucosa gástrica, já que o extrato não apresentou atividade no modelo de úlcera induzida por ácido acético.

\section{AGRADECIMENTOS}

Agradecemos ao Prof. Dr. Keigo Minami pela colaboração na aquisição da espécie vegetal, ao Prof. Dr. Vinícius Castro Souza e Fiorella Fernanda Mazine, pela identificação da espécie vegetal.

\section{REFERÊNCIAS}

Agra MF, França PF, Barbosa-Filho JM 2007. Synopsis of the plants known as medicinal and poisonous in Northeast of Brazil. Rev Bras Farmacogn 17: 114140.

Agra MF, Silva KN, Basílio IJLD, França PF, Barbosa-Filho JM 2008. Survey of medicinal plants used in the region Northeast of Brazil. Rev Bras Farmacogn 18: 472-508.

Albiero ALM, Sertié JAA, Bacchi EM 2002. Antiulcer activity of Sapindus saponaria L. in the rat. $J$. Ethnopharmacol 82: 41-44.

Auricchio MT 2001. Estudo farmacognóstico de folhas de Eugenia uniflora L. São Paulo, 128p. Dissertação de Mestrado - Faculdade de Ciências Farmacêuticas, Universidade de São Paulo.

Barros SBM, Teixeira DS, Aznar AE, Moreira Jr. JÁ, Ishii I, Freitas PCD 1996. Antioxidant activity of ethanolic extracts or Pothomorphe umbellata L. Miq. (Pariparoba). Cienc Cult 48: 114-116.

Barroso GM 1984. Sistemática de angiospermas do Brasil. Viçosa: Universidade Federal de Viçosa.

Birdane FM, Cemek M, Birdane YO, Gülçin I, Büyukokuroglu ME 2007. Beneficial effects of Foeniculum vulgare on ethanol-induced acute gastric mucosal injury in rats. World J Gastroenterol 13: 607-611.

Borrelli F, Izzo AA 2000. The plant kingdom as a source of anti-ulcer remedies. Phytother Res 14: 581-591.

Brunton LL 1996. Fármacos para controle da acidez gástrica e tratamento de úlceras pépticas. In: Hardman JG, Limberd LE, Molinoff PB, Ruddon RW, Gilman AG (eds.) Goodman \& Gilman as bases farmacológicas da terapêutica. 9.ed. Rio de Janeiro: McGraw-Hill, p.663-674.

Carbonezi CA, Hamerski L, Gunatilaka AAL, Cavalheiro A, Castro-Gamboa I, Silva DHS, Furlan M, Young MCM, Lopes MN, Bolzani VS 2007. Bioactive flavone dimers from Ouratea multiflora (Ochnaceae). Rev Bras Farmacogn 17: 319-324.

Cravo AB 1994. Frutas e ervas que curam: a panacéia vegetal. 4.ed. São Paulo: Hemus.

Di Stasi LC, Hiruma-Lima CA 2002. Plantas medicinais na Amazônia e na Mata Atlântica. São Paulo: Editora UNESP, p.323-330.

European Pharmacopoeia 1996. 3.ed. Strasbourg: Council of Europe. p.930. 
Fisher AA, Le Couteur DG 2001. Nephrotoxicity and hepatotoxicity of histamine $\mathrm{H}_{2}$ receptor antagonists. Drug Safety 24: 39-57.

Gonzalez FG, Portela TY, Stipp EJ, Di Stasi LC 2001. Antiulcerogenic and analgesic effects of Maytenus aquifolium, Sorocea bomplandii and Zolernia ilicifolia. J Ethnopharmacol 77: 41-47.

Gonzalez FG, Di Stasi LC 2002. Anti-ulcerogenic and analgesic activities of the leaves of Wilbrandia ebracteata in mice. Phytomedicine 9: 125-134.

Gonzalez P, Soriano V, Lopez P, Niveiro E 2002. Anaphylaxis to proton pump inhibitors. Allergol Immunopathol 30: $342-343$

Hiruma-Lima CA, Calvo TR, Rodrigues CM, Andrade FDP, Vilegas W, Souza Brito ARM 2006. Antiulcerogenic activity of Alchornea castaneaefolia: effects on somatostatin, gastrin and prostaglandin. $J$ Ethnopharmacol 104: 215-224.

Iha SM, Migliato KF, Vellosa JCR, Sacramento LVS, Pietro RCLR, Isaac VLB, Brunetti IL, Corrêa MA, Salgado HRN 2008. Estudo fitoquímico de goiaba (Psidium guajava L.) com potencial antioxidante para o desenvolvimento de formulação fitocosmética. Rev Bras Farmacogn 18: 387-393.

La Casa C, Villegas I, Alarcón de la Lastra C, Motilva V, Martín Calero MJ 2000. Evidence for protective and antioxidant properties of rutin, a natural flavone, against ethanol induced gastric lesions. $J$ Ethnopharmacol 71: 45-53.

Lewis DA, Hanson PJ 1991. Anti-ulcer drugs of plant origin. Prog Med Chem 28: 201-231.

Lima ZP, Severi JA, Pellizzon CH, Brito ARMS, Solis PN, Cáceres A, Girón LM, Vilegas W, Hiruma-Lima CA 2006. Can the aqueous decoction of mango flowers be used as an antiulcer agent? J Ethnopharmacol 106: 29-37.

Lorenzi H, Abreu Matos FJ 2002. Plantas medicinais no Brasil: nativas e exóticas cultivadas. Nova Odessa: Instituto Plantarum.

Marhuenda E, Martin MJ, Alarcon de la Lastra C 1993. Antiulcerogenic activity of aescine in different experimental models. Phytother Res 7: 13-16.

Markman BEO 2002. Caracterização farmacognóstica de Campomanesia xanthocarpa Myrtaceae. São Paulo, 167p. Dissertação de Mestrado - Faculdade de Ciências Farmacêuticas, Universidade de São Paulo.

Marques DA, Foglio MA, Morgante PG, Sluys MAV, Shepherd SLK 2006. Biotechnology approaches for production of antiulcerogenic dihydro-epideoxyarteannuin B isolated from Artemisia annua L. Rev Bras Farmacogn 16: 291-299.

Matos FJA 1988. Introdução à fitoquímica experimental. Coleção ciência 3, Editora Universidade do Ceará, p.35-80.

Mello JCP, Santos SC 2004. Taninos. In: Simões CMO, Schenkel EP, Gosmann G, Mello JCP, Mentz LA, Petrovick PR. Farmacognosia: da planta ao medicamento. 5.ed. Porto Alegre: UFRGS; Florianópolis: UFSC, p.615-656.

Mensor LL, Menezes FS, Leitão GG, Reis AS, Santos TC, Coube CS, Leitão SG 2001. Screening of Brazilian plant extracts for antioxidant activity by the use of DPPH free radical method. Phytother Res 15: $127-$
130.

Mizui T, Doteuchi M 1983. Effect of polyamines on acidified ethanol-induced gastric lesion in rats. Jpn $J$ Pharmacol 33: 939-945.

Mota KSL, Pita JCLR, Estevam EC, Medeiros VM, Tavares JF, Agra MF, Diniz MFFM, Silva MS, Batista LM 2008. Evaluation of the toxicity and antiulcerogenic activity of the ethanol extract of Maytenus obtusifolia Mart. Leaves. Rev Bras Farmacogn 18: 441-446.

Pihan G, Regillo C, Szabo S 1987. Free radicals and lipid peroxidation in ethanol- or aspirin-induced gastric mucosal injury. Dig Dis Sci 32: 1395-1401.

Pio Correa M 1969. Dicionário das plantas úteis do Brasil e das exóticas cultivadas. Rio de Janeiro: Instituto Brasileiro de Desenvolvimento Florestal, v.4, p.427.

Puurunen J, Huttunen P, Hirvonen J 1980. Is ethanol-induced damage of the gastric mucosa a hyperosmotic effect?: comparative studies on the effects of ethanol, some other hyperosmotic solutions and acetylsalicylic acid on rat gastric mucosa. Acta Pharmacol Toxicol 47: 321-327.

Ra A, Tobe SW 2004. Acute interstitial nephritis due to pantoprazole. Ann Pharmacother 38: 41-45.

Rang HP, Dale MM, Ritter JM, Moore PK 2004. Farmacologia. 5.ed. Rio de Janeiro: Elsevier, p.419-433.

Robert A 1979. Cytoprotection by prostaglandins. Gastroenterology 77: 761-767.

Rodriguez JA, Hiruma-Lima CA, Souza Brito AR 2004. Antiulcer activity and subacute toxicity of transdehydrocrotonin from Croton cajucara. Hum Exp Toxicol 23: 455-461.

Sabesin SM 1993. Safety issues relating to long-term treatment with histamine H2-receptor antagonists. Aliment Pharmacol Ther.7: 35-40.

Silvério MS, Sousa OV, Del-Vechio-Vieira G, Miranda MA, Matheus FC, Kaplan MAC 2008. Propriedades farmacológicas do extrato etanólico de Eremanthus erythropappus (DC.) McLeisch (Asteraceae). Rev Bras Farmacogn 18: 430-435.

Slowing K, Carretero E, Villar A 1996. Anti-inflammatory compounds of Eugenia jambos. Phytother Res 10: S126-S127.

Stocks J, Gutteridge JMC, Sharp RJ, Dormandy TL 1974. Assay using brain homogenate for measuring the antioxidant activity of biological fluids. Clin Sci Mol Med 47: 215-222.

Takagi K, Okabe S, Saziki R 1969. A new method for the production of chronic gastric ulcer in rats and the effect of several drugs on its healing. Jap $J$ Pharmacol 19: 418-426.

Wichtl M 1971. Die Pharmakognostisch-Chemische Analyse. Akademische Verlagsgesellschaft, Frankfurt am Main, p.416.

Zlabek JA, Anderson CG 2002. Lansoprazole-induced thrombocytopenia. Ann Pharmacother 36: 809-811. 